\title{
Pengembangan Perangkat Pembelajaran Matematika dengan Model Pembelajaran Kooperatif Tipe Numbered Heads Together pada Materi Aritmatika Sosial
}

\author{
Fitriana Yolanda ${ }^{1}$, Asmawati Hasanah ${ }^{2}$ \\ 1,2 Program Studi Pendidikan Matematika, Universitas Islam Riau, \\ Jl. Kaharuddin Nasution no. 113, Simpang Tiga, Kota Pekanbaru, Indonesia \\ fitrianayolanda@edu.uir.ac.id
}

\begin{abstract}
The purpose of this study was to produce a product of mathematics learning tools in the form of a Learning Implementation Plan (RPP) and Student Worksheet (LKPD) with a cooperative learning model of the Numbered Heads Together type on social arithmetic material for class VII SMP which was tested for validity. This research is a development research or Research and Development (R\&D) by developing learning tools using the ADDIE model which consists of 5 stages, namely the Analysis stage, the Design stage, the development stage, the Implementation stage, and the Evaluation stage (evaluation). In the ADDIE model, the researcher did not use the Implementation stage and the Evaluation stage because in the 2020/2021 school year there was a Covid-19 pandemic so that the learning process was carried out online or online. The data collection instruments were in the form of RPP validation sheets and LKPD validation sheets. The data collection technique was carried out using a non-test technique using a validation sheet. The data analysis technique used descriptive statistical analysis. The results of the study obtained an average RPP validation of $87.76 \%$ with a very valid category, and an average LKPD validation of $88.52 \%$ with a very valid category. While the average RPP validation for each assessment aspect was $88.32 \%$ with a very valid category, and the average LKPD validation for each assessment aspect was $89.19 \%$ with a very valid category. Based on the results of the study, it was concluded that this development research produced mathematics learning tools in the form of lesson plans and LKPD which were tested for validity.
\end{abstract}

Keywords: RPP, LKPD, Cooperative, Numbered Heads Together

\begin{abstract}
Abstrak
Tujuan penelitian ini untuk menghasilkan produk perangkat pembelajaran matematika berupa Rencana Pelaksanaan Pembelajaran (RPP) dan Lembar Kerja Peserta Didik (LKPD) dengan model pembelajaran kooperatif tipe Numbered Heads Together pada materi aritmatika sosial kelas VII SMP yang teruji kevalidannya. Penelitian ini merupakan penelitian pengembangan atau Research and Development (R\&D) dengan mengembangkan perangkat pembelajaran menggunakan model ADDIE yang terdiri dari 5 tahap, yaitu tahap Analysis (analisis), tahap Design (desain), tahap development (pengembangan), tahap Implementation (Pelaksanaan), dan tahap Evaluation (evaluasi). Pada model ADDIE peneliti tidak menggunakan tahap Implementation (Pelaksanaan), dan tahap Evaluation (evaluasi) dikarenakan pada tahun ajaran 2020/2021 sedang terjadi pandemi Covid-19 sehingga proses pembelajaran dilaksanakan secara online atau daring. Instrumen pengumpulan data berupa lembar validasi RPP dan lembar validasi LKPD. Adapun teknik pengumpulan data dilakukan dengan teknik nontes dengan menggunakan lembar validasi. Teknik analisis data menggunakan analisis statistik deskriptif. Hasil penelitian diperoleh rata-rata validasi RPP sebesar 87,76\% dengan kategori sangat valid, dan rata-rata validasi LKPD sebesar 88,52\% dengan kategori sangat valid. Sedangkan rata-rata validasi RPP setiap aspek penilaian diperoleh sebesar 88,32\% dengan kategori sangat valid, dan rata-rata validasi LKPD setiap aspek penilaian diperoleh sebesar $89,19 \%$ dengan kategori sangat valid. Berdasarkan hasil penelitian diperoleh kesimpulan bahwa penelitian pengembangan ini menghasilkan perangkat pembelajaran matematika berupa RPP dan LKPD yang teruji kevalidannya.
\end{abstract}

Kata kunci: RPP, LKPD, Kooperatif, Numbered Heads Together

Copyright (c) 2022 Fitriana Yolanda, Asmawati Hasanah

$\triangle$ Corresponding author: Fitriana Yolanda

Email Address: fitrianayolanda@edu.uir.ac.id (Jl. Kaharuddin Nasution no. 113, Simpang Tiga)

Received 22 December 2021, Accepted 14 February 2022, Published 01 March 2022

\section{PENDAHULUAN}

Matematika merupakan ilmu universal yang mempunyai peranan penting dalam pendidikan dan dalam kehidupan. Matematika juga merupakan salah satu bidang studi yang mendukung dalam 
perkembangan ilmu pengetahuan dan teknologi. Menurut Yolanda \& Wahyuni (2020) yang menjadi ratu sekaligus pelayanan ilmu dalam berbagai bidang ilmu yaitu matematika. Dengan adanya matematika siswa dapat berpikir secara kritis dan logis dengan memecahkan masalah dalam bahasa matematika di kehidupan sehari-hari. Hal ini sejalan dengan pendapat (Arthaningsih \& Komang, 2018; Yolanda \& Wahyuni, 2020; Ramadanti et al, 2021; Munawarah, 2017; Retnowati et al, 2021; Ananda et al, 2021) bahwa salah satu mata pelajaran yang dipelajari secara berkesinambungan mulai dari sekolah dasar hingga pendidikan tinggi agar dapat membekali siswa dengan kemampuan berpikir kritis, logis, analitis, sistematis, inovatif, memecahkan masalah, bernalar dan kreatif yaitu matematika.

Mengingat akan pentingnya peranan matematika maka upaya yang dilakukan untuk dapat memperbaiki sistem pengajaran tidak hanya memerlukan peran guru saja, akan tetapi perkembangan perangkat pembelajaran khususnya dalam pembelajaran matematika juga harus ditingkatkan. Tanjung \& Nababan (2018) menyatakan bahwa pada satuan pendidikan setiap guru berkewajiban agar dapat merencanakan dan menyusun suatu perangkat pembelajaran secara sistematis dan lengkap sehingga proses pembelajaran yang berlangsung di dalam kelas menjadi menyenangkan, menantang, inspiratif, interaktif dan dapat memotivasi siswa agar ikut berpatisipasi aktif, serta dapat memberikan ruang yang memadai untuk siswa agar menyesuaikan minat, bakat dan psikologis siswa serta perkembangan fisik siswa. Kurikulum 2013 menekankan kegiatan pembelajaran yang lebih mengaktifkan siswa. Dalam hal ini guru dituntut untuk melakukan inovasi atau beraneka ragam dalam kegiatan proses pembelajaran dalam kelas. Salah satu caranya adalah dengan mengembangkan perangkat pembelajaran matematika yang memenuhi tuntutan kurikulum 2013.

Perangkat pembelajaran yang baik yaitu perangkat pembelajaran yang kegiatan pembelajarannya dapat membuat peserta didik ikut berperan aktif dan lebih termotivasi dalam proses pembelajaran. Hal ini sejalan dengan pendapat Trianto (2015) proses pembelajaran pada setiap satuan pendidikan harus interaktif, inspiratif menyenangkan, menantang, dan memotivasi peserta didik agar berpartisipasi aktif dalam kegiatan pembelajaran. Perangkat pembelajaran dalam satuan pendidikan melipuli Silabus, RPP, LKPD, buku, dan lain-lain. Nurdin \& Adrianton (2016) secara singkat berpendapat bahwa perangkat pembelajaran yang berisikan garis besar (outline) yang akan dikerjakan oleh pendidik maupun peserta didik selama proses pembelajaran berlangsung baik untuk satu kali tatap muka atau beberapa kali tatap muka yaitu rencana pelaksanaan pembelajaran (RPP). Kemudian (Rizkiah \& Komarudin, 2018; Rewatus et al, 2020) LKPD adalah salah satu fasilitas pembelajaran yang dapat dipakai oleh pendidik untuk meningkatkan aktivitas serta mendorong agar terciptanya proses berpikir peserta didik sehingga dapat membantu peserta didik memecahkan masalah dalam proses pembelajaran.

Oleh karena itu inti dalam kegiatan pembelajaran terkandung dalam sebuah perangkat pembelajaran, jika perangkat pembelajaran yang dikembangkan bagus atau menarik dalam proses 
pembelajaran maka hal itu juga yang akan tercipta pada saat proses pembelajaran serta dapat memotivasi siswa untuk belajar dan meningkatkan hasil belajar.

Berdasarkan hasil wawancara peneliti kepada salah satu guru matematika pada tanggal 6 Oktober 2020 di SMPN 6 Siak Hulu kelas VII maka didapatkan informasi antara lain yaitu, (1) Perangkat pembelajaran yang digunakan guru matematika SMPN 6 Siak Hulu sudah mengacu pada kurikulum 2013 dengan pendekatan saintifik tetapi saat proses pembelajaran di dalam kelas guru menggunakan metode ceramah, (2) ketidak sesuaian waktu pembelajaran di RPP pada proses pembelajaran (3) guru menggunakan pendekatan saintifik pada RPP namun pada saat proses pembelajaran tidak sesuai dengan langkah-langkah pembelajaran yang tertulis pada RPP (4) Guru belum mengenal model pembelajaran kooperatif tipe Numbered Head Together, (5) Guru hanya memberikan soal-soal latihan yang terdapat di dalam buku pelajaran dan tidak menggunakan LKPD, sehingga motivasi dan minat belajar peserta didik kurang.

Berdasarkan permasalahan dan solusi di atas peneliti menggunakan model pembelajaran kooperatif tipe Numbered Heads Together. Model pembelajaran kooperatif yaitu model pembelajaran yang mengutamakan kerja sama diantara siswa atau biasanya diskusi kelompok untuk mencapai tujuan pembelajaran dan hasil belajar yang memuaskan. Pembelajaran kooperatif secara umum dapat diartikan sebagai suatu proses pembelajaran yang dilakukan di dalam kelas, dirancang untuk membatu peserta didik untuk mengerjakan tugas-tugas dalam kelompok belajar yang heterogen sehingga tercapai tujuan pembelajaran (Yolanda, 2019; Fathurrohman, 2016). Oleh karena itu dengan pembelajaran kooperatif ini diharapkan agar peserta didik dapat berperan aktif dan dapat memahami materi dalam proses belajar mengajar. Pembelajaraan kooperatif dapat membantu siswa menyampaikan setiap ide atau gagasannya pada saat diskusi, dan tidak hanya terpaku pada guru saja saat belajar, sehingga siswa dapat meningkatkan pemahaman dan prestasi akademik baik untuk dirinya sendiri maupun untuk kelompok.

Model pembelajaran kooperatif tipe Numbered Heads Together atau biasa disebut dengan kepala bernomor sruktur merupakan salah satu kegiatan pembelajaran yang sesuai dalam pembelajaran matematika. Shoimin (2014) secara ringkas berpendapat bahwa Numbered Heads Together merupakan suatu tipe pembelajaran yang dilakukan dengan cara diskusi kelompok yang setiap anggota kelompok bertanggung jawab atas tugas dalam kelompoknya, sehingga tidak ada perbedaan disetiap anggota dalam kelompok, peserta didik dapat bertukar pendapat dalam proses diskusi. Numbered Heads Together menuntut semua anggota kelompoknya untuk memahami materi yang diberikan, karena mereka akan diundi melalui nomor untuk menentukan siapa yang akan menyampaikan hasil diskusinya. Anggota kelompok juga akan dipilih secara heterogen, yaitu siswa berkemampuan rendah, sedang dan tinggi.

Pada penelitian ini peneliti memilih materi Aritmatika Sosial pada kelas VII SMP. Inayah (2018) secara singkat berpendapat bahwa aritmatika sosial merupakan materi pembelajaran yang sering dijumpai dalam kehidupan sehari-hari, namun pada nyatanya banyak dari peserta didik belum 
memahami materi tersebut padahal materi ini sangat awam bagi peserta didik. Nurwati et al, (2018) secara singkat berpendapat bahwa kesulitan peserta didik dalam memahami materi aritmatika sosial dikarenakan soal yang disajikan berbentuk soal cerita. Dari permasalahan tersebut maka peneliti memilih materi Aritmatika Sosial dalam mengembangkan perangkat pembelajaran matematika dengan model pembelajaran Kooperatif tipe Numbered Heads Together.

Dari permasalahan dan penjelasan yang telah dipaparkan maka peneliti tertarik melakukan penelitian dengan judul "Pengembangan Perangkat Pembelajaran Matematika Dengan Model Pembelajaran Kooperatif Tipe Numbered Heads Together pada Materi Aritmatika Sosial di Kelas VII SMP”. Tujuan penelitian ini untuk menghasilkan produk perangkat pembelajaran matematika berupa Rencana Pelaksanaan Pembelajaran (RPP) dan Lembar Kerja Peserta Didik (LKPD) dengan model pembelajaran Kooperatif Tipe Numbered Heads Together pada materi aritmatika sosial kelas VII SMP yang teruji kevalidannya.

\section{METODE}

Pada penelitian ini peneliti menggunakan jenis penelitian pengembangan atau yang dikenal sebagai Research and Devolepment (R \& D). Menurut Sanjaya (2013) secara singkat menyatakan bahwa penelitian dan pengembangan ( $\&$ D) ialah suatu proses untuk mengembangkan dan melakukan validasi terhadap suatu produk pendidikan. Jenis model penelitian pengembangan ini yaitu model pengembangan ADDIE. ADDIE (Analysis-Design-Development-Implementation-Evaluation) merupakan model desain pembelajaran yang bersifat umum. Menurut Rohman \& Amri (2013) model ADDIE menggunakan lima tahap pengembangan yaitu;(1) Analysis (analisa); (2) Design (desain/ perancangan); (3) Development (pengembangan); (4) Implementation (implementasi/eksekusi); (5) Evaluation (evaluasi/umpan balik). Menurut Mulyatiningsih (2011) secara singkat menyatakan dilihat dari langkah-langkah pengembangan produk, model pengembangan penelitian ADDIE lebih rasional dan lebih lengkap, sehingga mudah untuk dipahami dan dilakukan. Tageh \& Kirna (2013) secara singkat berpendapat bahwasannya model pengembangan ADDIE disusun secara terprogram dengan urutan-urutan sistematis dalam upaya pemecahan belajar yang berkaitan dengan sumber belajar yang sesuai dengan kebutuhan dan karakteristik pembelajaran. Peneliti memodifikasi untuk dapat digunakan sesuai dengan kebutuhan, modifikasi juga didasarkan pada kondisi yang saat ini dialami yaitu kondisi masih mewabahnya virus covid-19 saat ini. Oleh sebab itu peneliti hanya menggunakan 3 tahap model pengembangan ADDIE yang diantaranya yaitu; analisis (analysis), desain (design), dan Pengembangan (development).

Instrumen pengumpulan data yang digunakan dalam penelitian ini adalah lembar validasi. Lembar validasi yang digunakana terdiri dari lembar validasi RPP dan lembar validasi LKPD. Penelitian ini menggunakan interval yaitu menggunakan skala likert. Pada penelitian ini, peneliti melakukan modifikasi skala likert dari Sugiono tersebut dengan tujuan yaitu agar menghindari 
jawaban ragu-ragu atau netral. Maka peneliti menggunakan jenis instrumen yang berupa lembar validasi dengan ketentuan pemberian skor yang diberikan yaitu sebagai berikut:

Tabel. 1 Modifikasi Kategori Penilaian Lembar Validasi

\begin{tabular}{|c|c|c|}
\hline No & Skor Penilaian & Kategori \\
\hline 1 & 4 & Sangat Baik \\
\hline 2 & 3 & Baik \\
\hline 3 & 2 & Kurang Baik \\
\hline 4 & 1 & Tidak Baik \\
\hline
\end{tabular}

Sumber: Modifikasi Sugiyono (2015)

Teknik analisis data yang digunakan dalam penelitian ini yaitu analisis data deskriptif yang mendeskripsikan validasi perangkat pembelajaran yang dikembangkan dengan menghitung skor dari setiap indikator instrumen pengumpulan data yang diisi oleh validator atau para ahli. Akbar (2017) berpendapat bahwa valid tidaknya sebuah perangkat pembelajaran ditentukan dengan mencocokan hasil validasi empirik dari hasil dengan kriteria validitas yang ditentukan. Menurut Akbar (2017) rumus untuk analisis tingkat validasi secara deskriptif adalah

$$
\begin{aligned}
\mathrm{Va}_{1} & =\frac{T S e}{T S h} \times 100 \% \\
\mathrm{Va}_{2} & =\frac{T S e}{T S h} \times 100 \% \\
\mathrm{Va}_{3} & =\frac{T S e}{T S h} \times 100 \% \\
\mathrm{Va}_{4} & =\frac{T S e}{T S h} \times 100 \%
\end{aligned}
$$

Kemudian untuk mengetahui tingkat validitasnya terlebih dahulu dihitung rata-ratanya dengan menggunakan rumus sebagai berikut:

$$
\mathrm{V}=\frac{V a_{1}+V a_{2}+V a_{3}+V a_{4}}{4}=\ldots \%
$$

Keterangan:

$\mathrm{V}=$ Validasi (gabungan)

$\mathrm{Va}_{1}=$ Validasi ahli ke-1

$\mathrm{Va}_{2}=$ Validasi ahli ke-2

$\mathrm{Va}_{3}=$ Validasi ahli ke-3

$\mathrm{Va}_{4}=$ Validasi ahli ke-4

TSe $=$ Total skor empirik yang dicapai

$\mathrm{TSh}=$ Total skor yang diharapkan

Hasil validasi dan hasil analisis validasi gabungan setelah diketahui tingkat presentasinya dapat disesuaikan atau dikonfirmasi dengan kriteria validasi berikut. 
Tabel. 2 Kriteria Validitas Menurut Penilaian Validator

\begin{tabular}{|l|l|l|}
\hline No & \multicolumn{1}{|c|}{ Kriteria Validitas } & \multicolumn{1}{c|}{ Tingkat Validitas } \\
\hline 1 & $\begin{array}{l}85,01 \%-100 \% \\
70,01 \%-85 \%\end{array}$ & $\begin{array}{l}\text { Sangat valid atau dapat digunakan tanpa revisi } \\
\text { Cukup valid atau dapat digunakan namun perlu revisi kecil }\end{array}$ \\
\hline 3 & $50,01 \%-70 \%$ & $\begin{array}{l}\text { Kurang valid, disarankan tidak dipergunakan karena perlu } \\
\text { revisi besar }\end{array}$ \\
\hline 4 & $01,00 \%-50 \%$ & Tidak valid, atau tidak boleh dipergunakan \\
\hline
\end{tabular}

Sumber: Akbar (2017)

\section{HASIL DAN DISKUSI}

\section{Hasil Tahap Analysis (Analisis)}

\section{Analisis Kinerja (Performance Analysis)}

Pada tahap pertama peneliti mengunakan tahap analisa untuk mendapatkan informasi mengenai perangkat pembelajaran yang digunakan oleh guru mata pelajaran matematika kelas VII di SMPN 6 Siak Hulu. Analisa dilakukan pada tanggal 6 Oktober 2020 dengan cara mewawancarai guru matapelajaran matematika kelas VII di SMPN 6 Siak Hulu, dan memperoleh hasil yang diantaranya sebagai berikut:

1. Perangkat pembelajaran yang digunakan guru matematika SMPN 6 Siak Hulu sudah mengacu pada kurikulum 2013 dengan pendekatan saintifik tetapi saat proses pembelajaran di dalam kelas guru menggunakan metode ceramah.

2. Ketidak sesuaian waktu pembelajaran di RPP pada proses pembelajaran.

3. Guru menggunakan pendekatan saintifik pada RPP namun pada saat proses pembelajaran tidak sesuai dengan langkah-langkah pembelajaran yang tertulis pada RPP.

4. Guru belum mengenal model pembelajaran kooperatif tipe Numbered Head Together

5. Guru hanya memberikan soal-soal latihan yang terdapat di dalam buku pelajaran dan tidak menggunakan LKPD, sehingga motivasi dan minat belajar peserta didik kurang.

\section{Analisis Kebutuhan (Need Analysis)}

Berdasarkan hasil wawancara dengan guru mata pelajaran matematika SMP Negeri 6 Siak Hulu, terdapat beberapa solusi untuk mengatasi persoalan tersebut, yang diantaranya;

1. Mengembangkan perangkat pembelajaran berupa silabus, RPP dan LKPD.

2. Perangkat pembelajaran matematika yang dikembangkan berdasarkan pada kurikulum 2013.

3. Perangkat pembelajaran matematika berupa RPP dan LKPD yang dikembangkan sesuai dengan kurikulum 2013 dengan menggunakan model pembelajaran kooperatif tipe Numbered Heads Together pada saat proses kegiatan pembelajaran, model pembelajaran ini mengharuskan peserta didik untuk aktif dan memahami materi pembelajaran karena model pembelajaran ini lebih menekankan tanggung jawab siswa terhadap pemahaman materi pembelajaran.

4. Peneliti mengembangkan LKPD yang mengacu pada RPP dengan warna, gambar, tampilan, dan permasalahan yang menarik, sehingga menimbulkan motivasi dan minat belajar peserta didik. 


\section{Hasil Tahap Design (Desain)}

Peneliti merancang perangkat pembelajaran berupa Rencana Pelaksanaan Pembelajaran (RPP), dan Lembar kerja Peserta Didik (LKPD) yang dikembangkan. Rencana Pelaksanaan Pembelajaran (RPP) disusun berdasarkan silabus sedangkan LKPD disusun menurut Rencana Pelaksanaan Pelaksanaan (RPP) yang telah dikembangkan. Pada penelitian ini peneliti mengambil materi Aritmatika Sosial yang dimana pada pertemuan pertama materi yang dipelajari yaitu penjualan, harga pembelian, untung dan rugi, pertemuan kedua diskon dan pajak, pertemuan ketiga Brutto, Netto, dan Tara, dan pertemuan keempat yaitu bunga tunggal. Pada tahap desain peneliti juga membuat instrumen berupa lembar validasi RPP dan lembar validasi LKPD. Adapun hasil desain LKPD dapat dilihat pada gambar dibawah ini

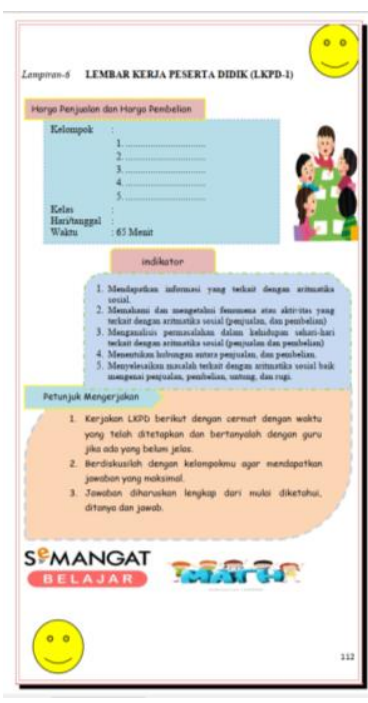

(a)

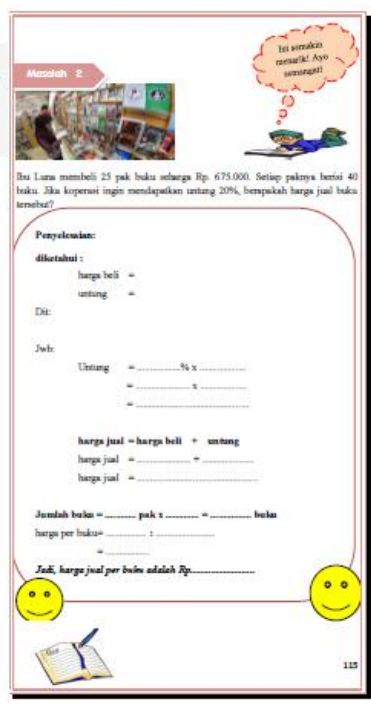

(e)

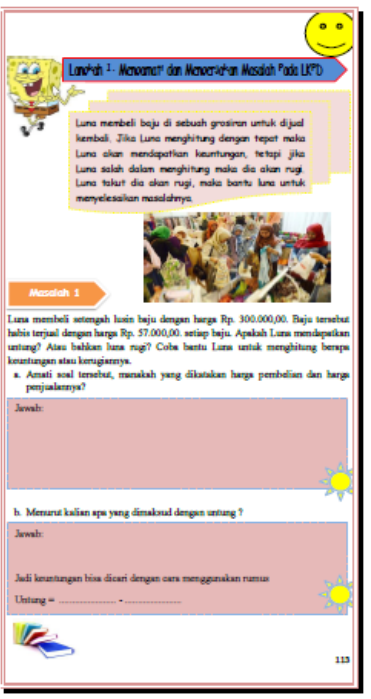

(b)

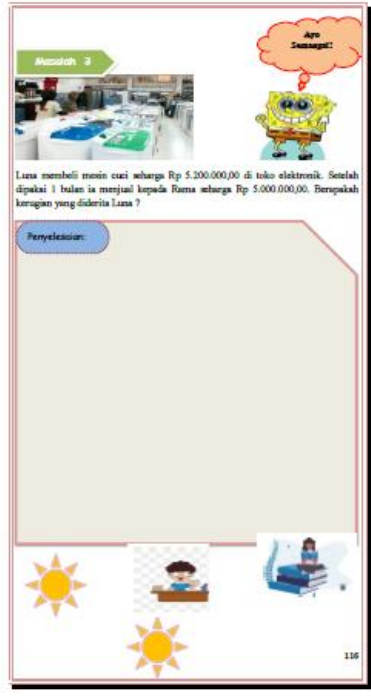

(f)

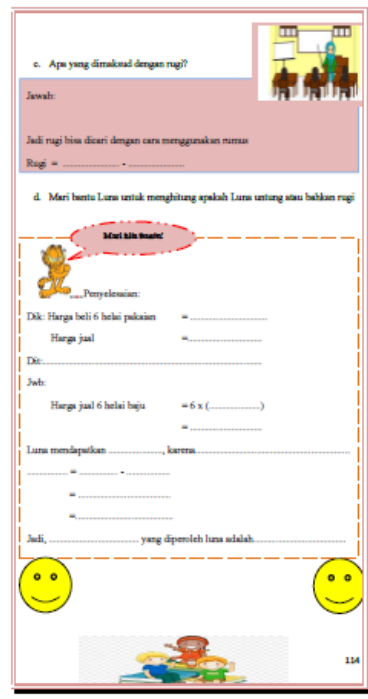

(c)

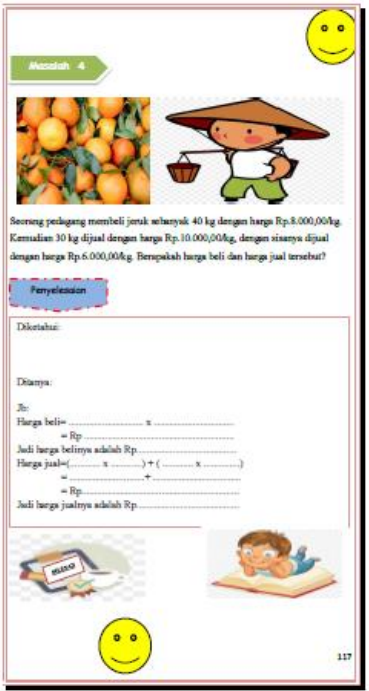

(g)

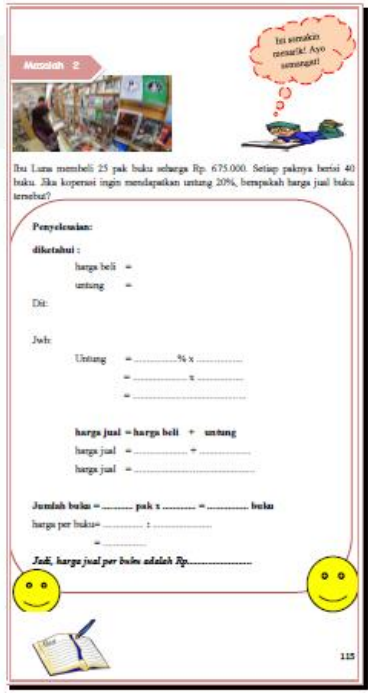

(d)

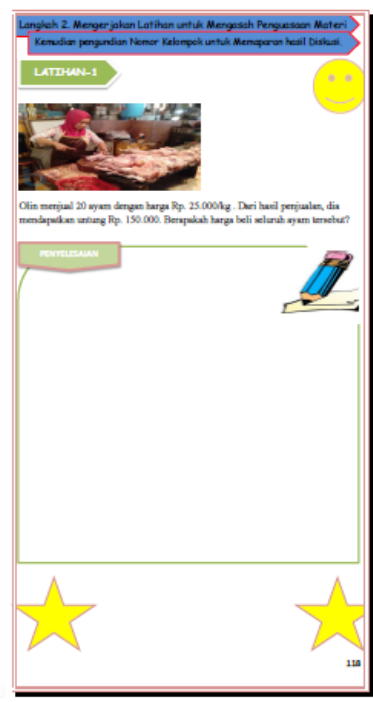

(h) 


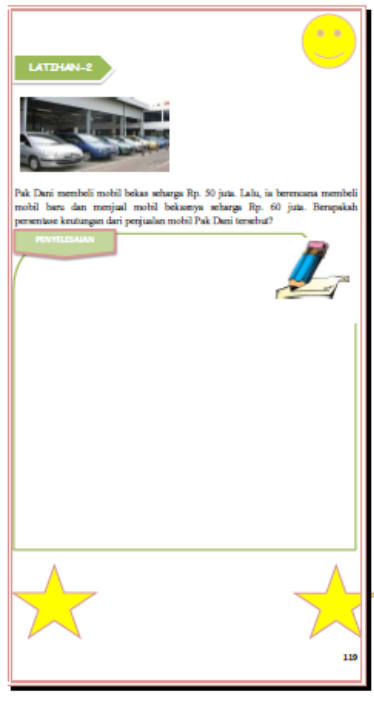

(i)

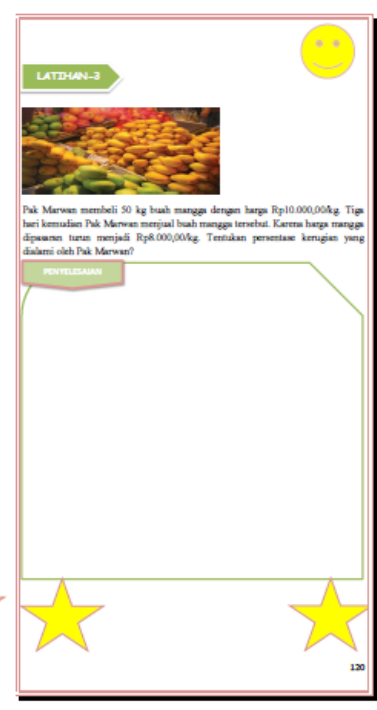

(j)

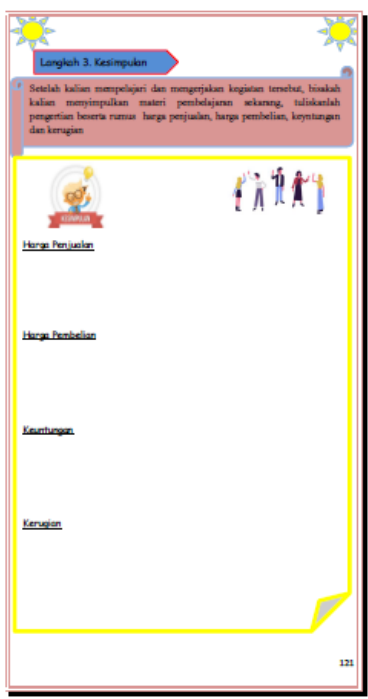

(k)

Gambar 1. Tampilan LKPD Pertemuan Satu

Gambar di atas merupakan tampilan LKPD pertemuan satu yang telah dirancang oleh peneliti dengan menggunakan model pembelajaran kooperatif tipe Numbered Heads Together. Pada gambar (h) merupakan tampilan LKPD tahap ketiga dari model pembelajaran kooperatif tipe Numbered Heads Together.

\section{Hasil Tahap Development (Pengembangan)}

\section{Produk Akhir Rencana Pelaksanaan Pembelajaran (RPP)}

Pada produk Rencana Pelaksanaan Pembelajaran (RPP) materi yang dibuat yaitu dengan mengacu pada kurikulum 2013 dengan memperhatikan fakta, konsep, prinsip dan prosedur. Pada kegiatan pembelajaran, langkah-langkah yang digunakan yaitu dengan model pembelajaran kooperatif tipe Numbered Heads Together (NHT). Berikut merupakan hasil revisi terhadap RPP yang sudah divalidasi oleh validator atau para ahli.

Tabel. 3 Saran dan Perbaikan dari Validator terhadap RPP

\begin{tabular}{|c|c|c|c|c|c|}
\hline RPP & \multicolumn{2}{|c|}{ Sebelum Revisi } & Saran & \multicolumn{2}{|c|}{ Setelah Revisi } \\
\hline RPP-1 & $\begin{array}{l}\text { Sekolah } \\
\text { Mata Pelajaran } \\
\text { Kelas/ Semester } \\
\text { Materi Pokok } \\
\text { Sub Materi } \\
\text { Tahun Ajaran } \\
\text { Alokasi Waktu }\end{array}$ & $\begin{array}{l}\text { SMP Negeri } 6 \text { Siak Hulu } \\
\text { : Matematika } \\
\text { : VII/ Genap } \\
: \text { Aritmatika Sosial } \\
: \text { Penjualan dan Pembelian } \\
: 2019 / 2020 \\
: 2 \times 40 \text { menit }\end{array}$ & $\begin{array}{l}\text { Redaksi } \\
\text { sub materi } \\
\text { tidak } \\
\text { sesuai } \\
\text { dengan } \\
\text { silabus }\end{array}$ & $\begin{array}{l}\text { Sekolah } \\
\text { Mata Pelajaran } \\
\text { Kelas/ Semester } \\
\text { Materi Pokok } \\
\text { Sub Maten } \\
\text { Tahun Ajaran } \\
\text { Alokasi Waktu }\end{array}$ & $\begin{array}{l}\text { : SMP Negen } 6 \text { Siak Hulu } \\
: \text { Matematika } \\
: \text { VII / Genap } \\
\text { :Antmatika Sosial } \\
: \text { Penjualan, Pembelian, Untung, dan Rug } \\
: 2019 / 2020 \\
: 2 \times 40 \text { menit }\end{array}$ \\
\hline
\end{tabular}


Pengembangan Perangkat Pembelajaran Matematika dengan Model Pembelajaran Kooperatif Tipe Numbered Heads Together pada Materi Aritmatika Sosial, Fitriana Yolanda, Asmawati Hasanah

\begin{tabular}{|c|c|c|c|}
\hline RPP-2 & 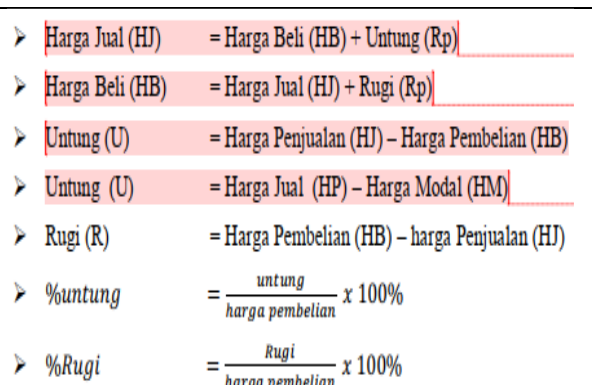 & $\begin{array}{l}\text { Perbaiki } \\
\text { materi } \\
\text { tambahkan } \\
\text { rumus dan } \\
\text { perbaiki } \\
\text { penulisan. }\end{array}$ & 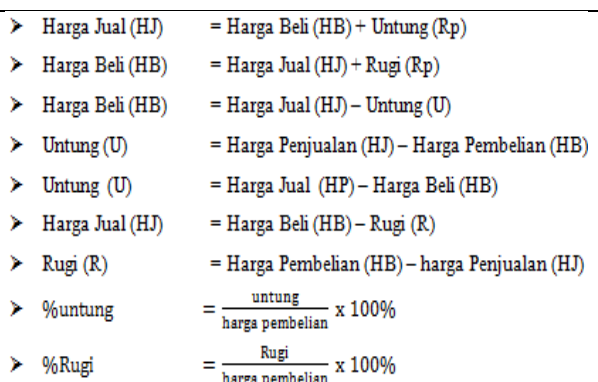 \\
\hline RPP-3 & $\begin{array}{l}\text { Gun memberi apersepsi kepada siswa dengan cara } \\
\text { mengaitkan materi aritmatika sosial dengan } \\
\text { pembelajaran yang akan dilakukan dengan pengalaman } \\
\text { peserta didik dengan materi sebelumnya. Seperti: } \\
\text { "karena materi kita jual beli, ibu tamya sama kalian } \\
\text { siapa disini yang pernah melakukan jual beli? Atau }\end{array}$ & $\begin{array}{l}\text { Perbaiki } \\
\text { apersepsi }\end{array}$ & $\begin{array}{l}\text { Guru memberi apersepsi kepada siswa dengan cara } \\
\text { mengaitkan materi aritmatika sosial dengan } \\
\text { pembelajaran yang akan dilakukan dengan pengalaman } \\
\text { peserta didik dengan materi sebelumnya. Seperti: } \\
\text { "sebelum kita mempelajari materi penjualan, } \\
\text { pembelian, untung dan rugi kita terlebih dahulu sudah } \\
\text { mempelajari materi perbandingan kan Rumus materi } \\
\text { perbandingan juga dapat kita gunakan pada materi kali } \\
\text { ini, nah ada yang tau tidak apa yang dimaks } \\
\text { penjualan, pengan } \\
\text { pelian, untung dan rugi?" }\end{array}$ \\
\hline RPP-4 & $\begin{array}{l}\text { Seorang pedagang sepatu menjulal sepasang sepatu kepada konsumen } \\
\text { dengan harga Rpg.000,00. Jika pada penijualan sepasang sepatu itu } \\
\text { pedagang mendapat untung sebesar Rp2.250,00, berapakah harga } \\
\text { pembelian sepatu itu dari pabriluya? }\end{array}$ & $\begin{array}{l}\text { Perbaiki } \\
\text { soal }\end{array}$ & $\begin{array}{l}\text { Seorang pedagang sepatu menjual sepasang sepatu kepada konsumen } \\
\text { dengan harga Rp90.000,00. Jika pada penjualan sepasang sepatu itutu } \\
\text { pedagang mendapat untung sebesar } 25 \% \text {, berapakah harga pembelian } \\
\text { sepatu itu dan pabriknya? }\end{array}$ \\
\hline
\end{tabular}

Setelah melakukan revisi produk, peneliti melakukan validasi kepada validator ahli. Lembar validasi terdiri dari 18 indikator yang dinilai oleh validator, dengan kriteria penilaian (1) tidak baik; (2) kurang baik; (3) baik; (4) sangat baik. Validasi diberikan kepada empat validator ahli pembelajaran. Hasil validasi untuk produk Rencana Pelaksanaan Pembelajaran (RPP) sebagai berikut:

Tabel.4 Hasil Validasi RPP Setiap Aspek Penilaian

\begin{tabular}{|l|c|c|c|c|c|c|}
\hline \multirow{2}{*}{\begin{tabular}{c}
\multirow{2}{*}{$\begin{array}{c}\text { Aspek yang } \\
\text { Dinilai }\end{array}$} \\
\cline { 2 - 7 }
\end{tabular}} & RPP-1 & RPP-2 & RPP-3 & RPP-4 & \multirow{2}{*}{ Rata-rata (\%) } & $\begin{array}{c}\text { Tingkat } \\
\text { Validitas }\end{array}$ \\
\hline Format RPP & $93,75 \%$ & $93,75 \%$ & $93,75 \%$ & $93,75 \%$ & $93,75 \%$ & Sangat Valid \\
\hline Aspek materi/ isi & $86,11 \%$ & $86,11 \%$ & $86,11 \%$ & $86,11 \%$ & $86,11 \%$ & Sangat Valid \\
\hline Aspek Bahasa & $93,75 \%$ & $93,75 \%$ & $93,75 \%$ & $93,75 \%$ & $93,75 \%$ & Sangat Valid \\
\hline Waktu & $84,37 \%$ & $87,50 \%$ & $90,62 \%$ & $84,37 \%$ & $86,72 \%$ & Sangat Valid \\
\hline Aspek Penilaian & $81,25 \%$ & $81,25 \%$ & $81,25 \%$ & $81,25 \%$ & $81,25 \%$ & Cukup Valid \\
\hline \multicolumn{7}{|c|}{ Rata-rata Total (\%) } \\
\hline
\end{tabular}

Tabel.5 Hasil Validasi RPP

\begin{tabular}{|c|c|c|c|c|c|}
\hline \multirow{2}{*}{ RPP } & \multicolumn{4}{|c|}{ Persentase Validitas (\%) } & \multirow{2}{*}{ Rata-rata $(\%)$} \\
\hline & V 1 & V 2 & V 3 & $\mathbf{V} 4$ & \\
\hline RPP-1 & $55,55 \%$ & $97,22 \%$ & $98,61 \%$ & $98,61 \%$ & $87,5 \%$ \\
\hline RPP-2 & $55,55 \%$ & $97,22 \%$ & $100 \%$ & $98,61 \%$ & $87,85 \%$ \\
\hline RPP-3 & $55,55 \%$ & $97,22 \%$ & $100 \%$ & $100 \%$ & $88,19 \%$ \\
\hline RPP-4 & $55,55 \%$ & $97,22 \%$ & $98,61 \%$ & $98,61 \%$ & $87,5 \%$ \\
\hline \multicolumn{5}{|c|}{ Rata-rata Total $(\%)$} & $87,76 \%$ \\
\hline \multicolumn{5}{|c|}{ Tingkat Validitas } & Sangat Valid \\
\hline
\end{tabular}


Berdasarkan tabel di atas, hasil validasi Rencana Pelaksanaan Pembelajaran (RPP) untuk setiap aspek penilaian diperoleh rata-rata sebasar $88,32 \%$ dengan kriteria sangat valid. Selanjutnya hasil rata-rata penilaian Rencana Pelaksanaan Pembelajaran (RPP) dari setiap validator secara keseluruhan, yaitu dengan rata-rata $87,76 \%$ juga dengan kriteria sangat valid.

\section{Produk Akhir Lembar Kerja Peserta Didik (LKPD)}

Pengembangan produk LKPD ini, peneliti memberikan masalah yang berkaitan dengan keseharian. Masalah yang diberikan dalam LKPD tersebut mengacu pada tujuan yang akan dicapai atau sesuai dengan indikator pembelajaran, supaya peserta didik dapat mudah memahami pelajaran yang disampaikan oleh guru. Berikut merupakan hasil validasi dan revisi LKPD.

Tabel. 6 Saran dan Perbaikan dari Validator terhadap LKPD

\begin{tabular}{|c|c|c|c|}
\hline LKPD & Sebelum Revisi & Saran & Setelah Revisi \\
\hline LKPD-1 & Waktu $\quad: 2 \times 40$ Menit & $\begin{array}{l}\text { Perbaiki } \\
\text { waktu pada } \\
\text { LKPD }\end{array}$ & Waktu $\quad: 65$ Menit \\
\hline LKPD-2 & $\begin{array}{l}\text { Luna membeli baju di sebuah grosiran untuk } \\
\text { dijual kembali. Jika Luna menghitung dengan- } \\
\text { tepat maka Luna akan mendapatkan keuntungan, } \\
\text { tetapi jika Luna salah dalam menghitung maka } \\
\text { dia akan rugi. }\end{array}$ & $\begin{array}{l}\text { Permasalahan } \\
\text { Kurang Jelas. }\end{array}$ & $\begin{array}{l}\text { Luna membeli baju di sebuah grosiran untuk dijual } \\
\text { kembali. Jika Luna menghitung dengan tepat maka } \\
\text { Luna akan mendapatkan keuntungan, tetapi jika } \\
\text { Luna takuh dalam menghitung maka dia akan rugi } \\
\text { menyelesaikan masalahnya. }\end{array}$ \\
\hline LKPD-3 & 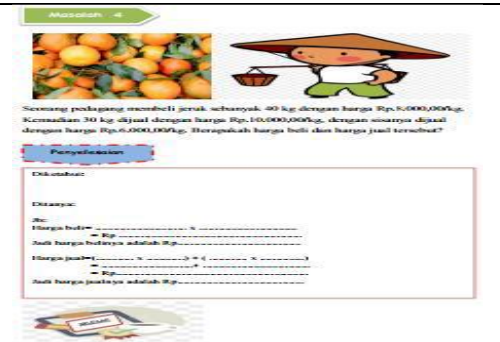 & $\begin{array}{l}\text { Tambahkan } \\
\text { gambar } \\
\text { edukasi. }\end{array}$ & 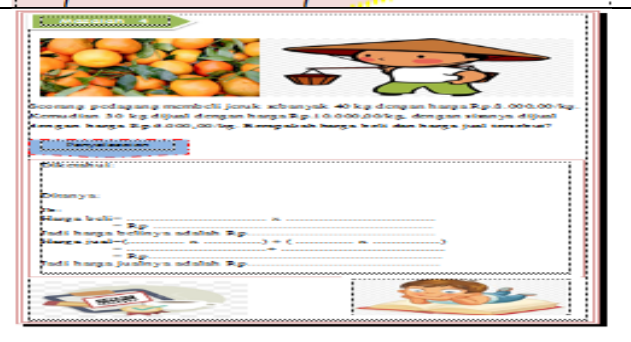 \\
\hline LKPD-4 & 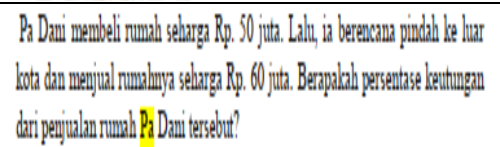 & $\begin{array}{l}\text { Perbaiki } \\
\text { penulisan dan } \\
\text { perbaiki soal }\end{array}$ & $\begin{array}{l}\text { Pak Danimembeli mobil bekas seharga Rp. } 50 \text { juta. Lalu, ia berencana membelle } \\
\text { mobil banu dan menjual mobil bekasnya seharga Rp. } 60 \text { juta. Berapakah } \\
\text { persentase keutungan dan penjualan mobil Pak Danitersebut? }\end{array}$ \\
\hline
\end{tabular}

Peneliti melakukan validasi kepada empat validator ahli. Lembar validasi teridiri dari 26 indikator yang dinilai oleh validator, dengan kriteria penilaian (1) tidak baik; (2) kurang baik; (3) baik; (4) sangat baik. Hasil validasi untuk produk Lembar Kerja Peserta Didik (LKPD) sebagai berikut:

Tabel. 7 Hasil Validasi LKPD Setiap Aspek Penilaian

\begin{tabular}{|l|c|c|c|c|c|c|}
\hline \multirow{2}{*}{$\begin{array}{c}\text { Aspek yang } \\
\text { Dinilai }\end{array}$} & \multicolumn{4}{|c|}{ Persentase Validasi (\%) } & \multirow{2}{*}{$\begin{array}{c}\text { Rata-rata } \\
(\%)\end{array}$} & $\begin{array}{c}\text { Tingkat } \\
\text { Validitas }\end{array}$ \\
\cline { 2 - 5 } & LKPD-1 & LKPD-2 & LKPD-3 & LKPD-4 & Sangat Valid \\
\hline Syarat Didaktik & $89,58 \%$ & $89,58 \%$ & $89,58 \%$ & $89,58 \%$ & $89,58 \%$ & San \\
\hline Syarat Isi & $86,25 \%$ & $86,25 \%$ & $86,25 \%$ & $86,25 \%$ & $86,25 \%$ & Sangat Valid \\
\hline Syarat Kontruksi & $92,50 \%$ & $92,50 \%$ & $92,50 \%$ & $93,75 \%$ & $92,81 \%$ & Sangat Valid \\
\hline
\end{tabular}




\begin{tabular}{|l|c|c|c|c|c|c|}
\hline Syarat Penyajian & $84,37 \%$ & $87,50 \%$ & $87,50 \%$ & $87,50 \%$ & $86,72 \%$ & Sangat Valid \\
\hline Aspek Waktu & $90,62 \%$ & $90,62 \%$ & $90,62 \%$ & $90,62 \%$ & $90,62 \%$ & Sangat Valid \\
\hline \multicolumn{3}{|c|}{ Rata-rata Total $\%)$} & $89,19 \%$ & Sangat Valid \\
\hline
\end{tabular}

Tabel. 8 Hasil Validasi LKPD

\begin{tabular}{|c|c|c|c|c|c|}
\hline \multirow{2}{*}{ LKPD } & \multicolumn{4}{|c|}{ Persentase Validitas (\%) } & \multirow{2}{*}{ Rata-rata (\%) } \\
\cline { 2 - 5 } & V 1 & V 2 & V 3 & V 4 & \\
\hline LKPD-1 & $58,65 \%$ & $97,11 \%$ & $99,03 \%$ & $99,03 \%$ & $88,46 \%$ \\
\hline LKPD-2 & $58,65 \%$ & $97,11 \%$ & $99,03 \%$ & $99,03 \%$ & $88,46 \%$ \\
\hline LKPD-3 & $58,65 \%$ & $97,11 \%$ & $99,03 \%$ & $99,03 \%$ & $88,46 \%$ \\
\hline LKPD-4 & $59,61 \%$ & $97,11 \%$ & $99,03 \%$ & $99,03 \%$ & $88,70 \%$ \\
\hline \multicolumn{5}{|c|}{ Tata-rata Total (\%) } & $88,52 \%$ \\
\hline \multicolumn{5}{|c|}{ Tingkat Validitas } & Sangat Valid \\
\hline
\end{tabular}

Berdasarkan tabel di atas, hasil validasi LKPD untuk setiap aspek penilaian diperoleh rata-rata sebasar 89,19\% dengan kriteria sangat valid. Selanjutnya hasil rata-rata penilaian RPP dari setiap validator secara keseluruhan, yaitu dengan rata-rata $88,52 \%$ juga dengan kriteria sangat valid. Dengan tercapainya kriteria valid dari perangkat pembelajaran yang telah dikembangkan, maka diperoleh suatu produk akhir berupa perangkat pembelajaran matematika dengan materi aritmatika sosial menggunakan model pembelajaran kooperatif tipe Numbered Heads Together yang valid sehingga layak digunakan dalam pembelajaran. Hal ini juga didukung oleh penelitian yang dilakukan oleh (1) Ernawati \& Wiwik (2021) menyatakan bahwa produk akhir berupa perangkat pembelajaran yaitu RPP dan LKPD yang telah dikembangkan dengan menggunakan model kooperatif tipe Numbered Heads Together (NHT) memperoleh hasil validasi sangat valid; (2) Sugianto (2017) menyatakan bahwa produk akhir berupa RPP dan LKPD memperoleh hasil validasi valid; dan (3) Yuliafarini (2019) menyatakan bahwa produk akhir berupa RPP dan LKPD memperoleh hasil validasi valid untuk digunakaan oleh peserta didik di dalam proses pembelajaran.

\section{KESIMPULAN}

Berdasarkan hasil penelitian yang terdapat pada pembahasan bahwasanya perangkat pembelajaran matematika yang dikembangkan dengan menggunakan model pembelajaran kooperatif tipe Numbered Heads Together, yang berupa Rencana Pelaksanaan Pembelajaran (RPP) mendapatkan hasil sangat valid dengan rata-rata validasi sebesar $87,76 \%$ dan rata-rata validasi setiap aspek penilaian sebesar 88,32\%. Sedangkan Lembar Kerja Peserta Didik (LKPD) mendapatkan hasil sangat valid dengan rata-rata validasi sebesar 88,52 dan rata-rata validasi setiap aspek penilaian sebesar $89,19 \%$, yang berarti telah dihasilkan perangkat pembelajaran matematika dengan model pembelajaran kooperatif tipe Numbered Heads Together (NHT) pada materi Aritmatika Sosial kelas VII SMP telah teruji kevalidannya. 


\section{REFERENSI}

Akbar, S. (2017). Instrumen Perangkat Pembelajaran. Bandung: Remaja Rosdakarya.

Ananda, M., Fauzi, K. M.A., \& Firmansyah. (2021). Pengembangan Perangkat Pembelajaran Matematika Berbasis Kontekstual Untuk Meningkatkan Kemampuan Komunikasi Matematis Siswa. Jurnal MathEducation Nusantara, 4(1), 28-37.

Arthaningsih, N. K. J., \& Komang, S.D. (2018). Pengaruh Model Pembelajaran Kooperatif Tipe Two Stay Two Stray Melalui Lesson Study Terhadap Hasil Belajar Matematika. Journal of Education Technology, 2(4), 128-136.

Ernawati, \& Wiwik. (2021). Pengembangan Perangkat Pembelajaran Matematika Dengan Menggunakan Model Kooperatif Tipe Numbered Head Together (NHT) Untuk Pokok Bahasan Persamaan Garis Lurus. Infinity: Jurnal Matematika Dan Aplikasinya (IJMA), 2(1), 11-21.

Fathurrohman, M. (2016). Model-Model Pembelajaran Inovatif. Yogyakarta: Ar-Ruzz Media.

Inayah, F.F. (2018). Penerapan Teori Situasi Didaktik Pada Materi Aritmatika Sosial. Kontinu: Jurnal Penelitian Didaktik Matematika, 2(2), 35-47.

Mulyatiningsih, E. (2011). Riset Terapan Bidang Pendidikan dan Teknik. Yogyakarta: UNY Press.

Munawarah. (2017). Pengembangan Perangkat Pembelajaran Matematika Dengan Menggunakan Pendekatan Kontekstual. MaPan: Jurnal Matematika Dan Pembelajaran, 5(2), 168-186.

Nurdin, S., \& Adrianton. (2016). Kurikulum dan Pembelajaran. Depok: PT. Rajagrafindo Persada.

Nurwati, S., Andari, T., \& Susanti, V. D. (2018). Pengembangan LKS Berbasis CTL Pada Materi Aritmatika Sosial Untuk Meningkatkan Kemampuan Matematis Siswa. Prosiding Silogisme Seminar Nasional Pendidikan Matematika Universitas PGRI Madiun 18 Juli 2018, 1(1), 159164.

Ramadanti, F., Mutaqin, A., \& Hendrayana, A. (2021). Pengembangan E-Modul Matematika Berbasis PBL (Problem Based Learning) pada Materi Penyajian Data untuk Siswa SMP. Jurnal Cendekia: Jurnal Pendidikan Matematika, 5(3), 2733-2745.

Retnowati, I.D., Siswono, T.Y.E., \& Wiryanto. (2021). Pengembangan Perangkat Pembelajaran Matematika Realistik Terintegrasi ICT Untuk Meningkatkan Kemampuan Berpikir Kritis Siswa. ANARGYA: Jurnal Ilmiah Pendidikan Matematika, 4(2), 129-135.

Rewatus, A., Leton, S.I., Fernandez, A.J., \& Suci, N.M. (2020). Pengembangan Lembar Kerja Peserta Didik Berbasis Etnomatematika Pada Materi Segitiga dan Segiempat. Jurnal Cendekia: Jurnal Pendidikan Matematika, 4(2), 645-656.

Rizkiah, A. W., \& Komarudin, N. (2018). LKPD Discussion Activity Terintegrasi Keislaman dengan Pendekatan Pictorial Riddle pada Materi Pecahan. Desimal: Jurnal Matematika, 1(1), 39-47.

Rohman, M., \& Amri, S. (2013). Strategi dan Desain Pengembangan Sistem Pembelajaran. Jakarta: Prestasi Pustaka.

Sanjaya, W. (2013). Penelitian Pendidikan, Jenis, Metode dan Prosedur. Jakarta: Kencana Prenada Media Group. 
Pengembangan Perangkat Pembelajaran Matematika dengan Model Pembelajaran Kooperatif Tipe Numbered Heads

Shoimin, A. (2014). 68 Model Pembelajaran Inovatif Dalam Kurikulum 2013. Yogyakarta: Ar-Ruzz Media.

Sugianto, L. (2017). Pengembangan Perangkat Pembelajaran Pada Materi Differensial Dengan Model Kooperatif Tipe Number Head Together (NHT). Prosiding Seminar Nasional Universitas Cokroaminoto Palopo, 3(1), 434-450.

Sugiyono. (2015). Metode Penelitian Kuantitatif, Kulitatif, $R \& D$. Bandung: Alfabeta.

Tageh, M.I., \& Kirna, M.I. (2013). Pengembangan Bahan Ajar Metode Penelitian Pendidikan dengan ADDIE Model. Jurnal IKA, 11(1), 12-26.

Tanjung, H. S., \& Nababan, S. A. (2018). Pengembangan Perangkat Pembelajaran Matematika Berorientasi Model Pembelajaran Berbasis Masalah (PBM) untuk Meningkatkan Kemampuan Berpikir Kritis Siswa SMA Se-Kuala Nagan Raya Aceh. GENTA MULIA: Jurnal Ilmiah Pendidikan, 9(2), 56-70.

Trianto. (2015). Model Pembelajaran terpadu Konsep, Stategi, dan Implementasinya dalam Kurikulum KTSP. Jakarta: Bumi Aksara.

Yolanda, F. (2019). Penerapan Pembelajaran Kooperatif Tipe Numbered Heads Together (NHT) untuk Meningkatkan Self-Efficacy Siswa. PHI: Jurnal Pendidikan Matematika, 3(1), 8-11.

Yolanda, F., \& Wahyuni, P. (2020). Pengembangan Bahan Ajar Berbantuan Macromedia Flash. SJME (Supremum Journal of Mathematics Education), 4(2), 170-177.

Yolanda, F., \& Wahyuni, P. (2020). Peningkatan Kemampuan Koneksi Matematis Mahasiswa Melalui Pembelajaran Matematika Kontekstual. ANARGYA: Jurnal Ilmiah Pendidikan Matematika, 3(1), 1-7.

Yuliafarini, F. E. (2019). Pengembangan Perangkat Pembelajaran Kooperatif Dengan Pendekatan Struktural Numbered Head Together (NHT) Menggunakan Model Four-D Materi Statistika. Jurnal Penelitian Dan Pengembangan Pendidikan, 3(3), 149-158. 